The chronological method assumed that the precisely known generation rates should lead to a constant ${ }^{231} \mathrm{~Pa} /{ }^{230} \mathrm{Th}$ ratio in young oceanic sediments, and that the ratio should decay exponentially with age in older sediments. Knowing the initial surface sediment ratio and the ratio in deeper sediments, the age of each deep sediment sample could be calculated.

This use of sedimentary ${ }^{231} \mathrm{~Pa} /{ }^{230} \mathrm{Th}$ seemed unassailable until other dating methods showed that it assigned incorrect ages $^{3-5}$. Further investigations showed that surface sediments do not start with constant ${ }^{231} \mathrm{~Pa} /{ }^{230} \mathrm{Th}$ : the ratio shows large variations from place to place and at the same site over time ${ }^{6-8}$. This variability was a puzzle whose cause has only become evident in recent years with studies of the oceanic chemistry of these isotopes ${ }^{9-11}$. Although both isotopes are 'particle-reactive' and attach themselves to particles which sink to the bottom, it has become clear that ${ }^{230} \mathrm{Th}$ is considerably more particle-reactive than ${ }^{231} \mathrm{~Pa}$. At particle flux levels typically seen in large ocean basins, ${ }^{230} \mathrm{Th}$ attaches itself to particles and is removed from the water column in a few decades; ${ }^{231} \mathrm{~Pa}$ is removed on a timescale of a century or more.

As a result of this difference in reactivity, most ${ }^{230} \mathrm{Th}$ falls to the bottom almost immediately below the site where it is generated, but a significant fraction of the ${ }^{231} \mathrm{~Pa}$ is transported laterally to sites of higher particle flux. For this reason, in recent years it has been considered that sedimentary ${ }^{231} \mathrm{~Pa} /{ }^{230} \mathrm{Th}$ is an indicator of past biological productivity ${ }^{12-14}$ because it is strongly correlated with total particle flux.

In a study that was initially aimed at using this indicator to examine changes in Atlantic biological productivity patterns between the present and the Last Glacial Maximum, Yu et al. uncovered a surprising result: there is ${ }^{231} \mathrm{~Pa}$ missing from the Atlantic Ocean. Almost all of this isotope must reside in oceanic sediments, because its concentration in sea water is lower than would be implied by its production rate. But $\mathrm{Yu}$ et al. found ${ }^{231} \mathrm{~Pa}$ to be clearly deficient throughout the surface sediments of the Atlantic Ocean, with an average ${ }^{231} \mathrm{~Pa} /{ }^{230} \mathrm{Th}$ more than 30 per cent below the production ratio. Conversely, they noted that ${ }^{231} \mathrm{~Pa} /{ }^{230} \mathrm{Th}$ was clearly increased in the surface sediments of the Southern Ocean by about the same amount. They surmise that the ${ }^{231} \mathrm{~Pa}$ missing from the Atlantic Ocean is conveyed into the Southern Ocean by NADW convection, to be removed there by the veil of particles created at the Antarctic Circumpolar Front.

This surprising deduction is compounded by their further discovery that the same pattern of Atlantic depletion and Antarctic enrichment is seen during the Last Glacial Maximum. They con- clude that the NADW (or more likely a shallower analogue) continued to export Atlantic waters into the southern and global oceans. This qualitative result is buttressed by their quantitative analysis which examines the sensitivity of ${ }^{231} \mathrm{~Pa}$ export from the Atlantic to changes in deep-water flow rates and changing productivity. The behaviour of ${ }^{231} \mathrm{~Pa}$ makes sense in terms of the time NADW spends in the Atlantic (about two centuries). Decade-scale resident ${ }^{230}$ Th cannot travel far along the conveyor, but century-scale resident ${ }^{231} \mathrm{~Pa}$ can move out of the basin in the time available. The export rate of the NADW-analogue during the Last Glacial Maximum must have been close to the present rate.

A persistent sceptic could argue that ${ }^{231} \mathrm{~Pa}$ is not actually missing from the Atlantic (either at present or during glacial times), and that the apparent deficiency is an artefact of the limited number of sites analysed. Yu and colleagues argue persuasively that this alternative is not probable, and so present a clear challenge to the sceptics: go out and find the missing ${ }^{231} \mathrm{~Pa}$.

Many investigators suspect that the NADW current is a key control on natural climate change during ice ages. If the results of Yu et al. are accepted, then that control must be exerted through changes in the mode of circulation (shallower or deeper flow, for example), rather than by an on-off cycle or any influence on global deep water characteristics.

Some insight could be derived from more complicated models with more degrees of freedom. Further data and modelling will either confirm and strengthen the results of $\mathrm{Yu}$ et al. or improve our understanding of oceanic radionuclide behaviour - a win-win situation.

Ed Boyle is in the Department of Earth and Planetary Sciences, Massachusetts Institute of Technology, 77 Massachusetts Avenue, Massachusetts 02139, USA.

1. Yu, E.-F., Francois, R. \& Bacon, M. P. Nature 379 689-694 (1996)

2. Rosholt, J. N., Emiliani, C., Geiss, J., Koczy, F. F. \& Wangersky, P. J. J. Geol. 69, 162-185 (1961)

3. Broecker, W. S. et al. Science 159, 297-300 (1968)

4. Broecker, W. S. \& vanDonk, J. Rev. Geophys. Space Phys. 8, 169-198 (1970)

5. Shackleton, N. J. \& Opdyke, N. D. Quat. Res. 3, 39-55 (1973).

DeMaster, D. thesis, Yale Univ. (1979).

7. Bacon, M. P. \& Rosholt, J. N. Geochim. cosmochim. Acta 46, 651-666 (1982).

8. Yang, H. S., Nozaki, Y., Sakai, H. \& Masuda, A. Geochim. cosmochim. Acta 50, 81-99 (1986).

9. Anderson, R. F., Bacon, M. P. \& Brewer, P. G. Earth planet. Sci. Lett. 62, 7-23 (1983).

10. Bacon, M. P. Phil. Trans. R. Soc. A325, 147-160 (1988).

11. Yu, E.-F. thesis, Woods Hole Oceanographic Institution/Massachusetts Institute of Technology (1994).

12. Anderson, R. F. et al. Earth planet. Sci. Lett. 96, 287-304 (1990)

13. Kumar, N., Gwiazda, R., Anderson, R. F. \& Froelich, P. N. Nature 362, 45-48 (1993).

14. Francois, R., Bacon, M. P., Altabet, M. A. \& Labeyrie L. D. Paleoceanography 8, 611-630 (1993)

\section{Romantic airs}

THOSE who have made love in an aircraft speak highly of the experience; indeed, they claim membership of the exclusive 'mile-high club'. Daedalus connects this fact with the bizarre rituals of certain dedicated masturbators, who halfsuffocate themselves with ropes or plastic bags to enhance the sensations of orgasm. Sometimes they overdo it, and are later found tragically dead. Both suffocation and aircraft altitudes, of course, reduce the level of oxygen in the body. It seems that sex is sexier with less oxygen.

Daedalus has an explanation. The biomolecule nitric oxide is a key mediator in penile erection and other aspects of the sexual process. It is destroyed by oxygen, which takes it to dinitrogen tetroxide (or in the body, to nitrate). Removing oxygen must extend the biochemical lifetime of nitric oxide, and intensify the sexual experience.

Artificial sources of nitric oxide seem to have the same effect. Nitrite stimulants, and even nitroglycerine anti-angina tablets, have been recommended as sexual aids. Yet such powerful sources of nitric oxide can have worrying side effects. It would seem better to extend the lifetime of the body's own nitric oxide, if a less drastic way can be found than oxygen starvation.

Daedalus notes that carbon monoxide reverses the destruction of nitric oxide by oxygen. It is preferentially oxidized instead, and should greatly extend the lifetime of nitric oxide in the body. A mere trace of carbon monoxide, comparable to the levels of nitric oxide in the body itself, should do - even the amount inhaled with cigarette smoke might be adequate. Indeed, this may explain the deplorably sexy image of the cigarette, and the power of the car as a vehicle of courtship (its exhaust contains both oxides). If so, the catalytic exhaust-purifier signals the end of a dream.

Daedalus is now testing these notions.

$\mathrm{He}$ is trying out various mixtures of oxygen-depleted air, nitric oxide and carbon monoxide on volunteers, seeking the formulation of greatest sexual impact. With luck oxygen depletion will turn out to be unnecessary, while the other gases will have their maximum effect at fairly harmless levels.

DREADCO will then market an inhaler which leaks these gases into the user's airstream. It will not obstruct normal breathing; the user will run no risk of suffocation. Daedalus is planning a neat design modelled on a classic sophisticated cigarette holder. The elegant seductions of old movies will be replayed for real in thousands of bedrooms.

David Jones 